chronic respiratory illness in patients with underlying disease such as mucoviscidosis, leukaemia, and Letterer-Siewe disease, and in these patients the respiratory complications are frequently the cause of death.

Patients with altered immunity may have unpredictable responses to measles virus. Thus they may have a rash but fail to produce antibody in serum, or on exposure to measles they fail to develop a rash. At least one child, a leukaemic, has died after receiving attenuated measles vaccine, with the development of giant cell pneumonia. ${ }^{5}$ Recently Pullen and colleagues $^{6}$ have reported atypical measles in three leukaemic children on immunosuppressive treatment; two developed encephalopathy and died, the third survived a giant cell pneumonia. The risks to leukaemic children of exposure to measles virus are clear; children with leukaemia and measles patients should not be admitted to the same general ward.

It is possible then to postulate that the common respiratory symptoms in measles are transient symptoms of a host-virus relationship characteristically producing giant cells, the natural evolution of which is the rejection of giant cells with eventual complete resolution. A few patients with altered immune states progress to a chronic respiratory illness, and necropsy in these cases has shown numerous multinuclear giant cells and the presence of measles virus. ${ }^{7} \mathrm{~A}$ small minority of patients die of giant cell pneumonia in the acute stage of measles, but the reasons for the occurrence of the complication at this stage of the illness are conjectural.

Secondary pulmonary infection is responsible for about half the mortality in measles. Millar ${ }^{8}$ reported a mortality of 2 per 1000 cases in Britain. Larger series of cases from developing countries with a much higher mortality rate suggest that respiratory complications also account for about half the deaths. ${ }^{910}$ Clinically, secondary respiratory infection is usually encountered when the patient is well on the way to recovery. Seven to 10 days after the onset of the rash fever returns, leucopenia is replaced by a neutrophilia, and the chest $x$-ray film may show consolidation. One of the common bacterial pathogens, pneumococci, $H$ influenzae, streptococci, and staphylococci, is usually found and antibiotic therapy started.

What of secondary viral infection as a possible cause of respiratory complication following measles? A recent paper by Warner and Marshall11 describes four children who developed severe lung disease after measles, and the authors considered that adenovirus infection was responsible for this complication, which resulted in one death. The difficulty with this sort of study on a few patients is to prove a causal relationship between two conditions which may happen to coexist in the same patient. Adenoviruses are commonly isolated from tonsils and other tissues without apparently causing any disease, yet they can on occasions produce severe chronic respiratory illness ${ }^{12} 13$ of the type described by Warner and Marshall in their patients after measles. One of their patients had a leucocytosis suggesting bacterial rather than viral secondary infection, though bacteriological cultures were not helpful. While on clinical and virological evidence these four children almost certainly suffered from measles, antibody studies relating both to measles virus and to adenovirus may have been altered by corticosteroids used in treatment.

Present views on respiratory complications in measles may be summarised as follows. Initially in wild measles respiratory symptoms are a characteristic part of the disease and are assumed to be due to a viral pneumonitis. In a small minority of patients this progresses to severe giant cell pneumonia and may cause death. In some developing countries this may be a relatively common pattern. Giant cell pneumonia is more characteristically a chronic illness in patients who are immunosuppressed by disease, such as leukaemia, or by cytotoxic drugs. Secondary bacterial infection is relatively common and important to diagnose, for antibiotics may be curative. Secondary viral infection has hardly been explored as a factor. in the complications, but Warner and Marshall, while not proving that adenoviruses are responsible, at least remind us to keep an open mind on the aetiology of one of the respiratory complications of measles.

${ }^{1}$ Papp, K, Revue d'Immunologie et de Thérapie Antimicrobienne, 1956, 20, 27. 2 Stryker, W A, American fournal of Diseases of Children, 1940, 59, 468.

3 Reiman, H A, Medicine, 1947, 26, 167.

4 Davidsohn, I, and Mora, J, Archives of Pathology, 1932, 14, 757.

5 Mitus, et al, American fournal of Diseases of Children, 1962, 103, 413.

6 Pullen, C R, et al, British Medical fournal, 1976, 1, 1562.

7 Enders, J F, et al, New England fournal of Medicine, 1959, 261, 875.

${ }^{8}$ Miller, D L, British Medical fournal, 1964, 2, 75.

9 Morley, D, British Medical fournal, 1969, 1, 297.

${ }^{10}$ Bwibo, N O, Tropical and Geographical Medicine, 1970, 22, 167.

11 Warner, J O, and Marshall, W C, British fournal of Diseases of the Chest, 1976, 70, 89.

\section{Hepatitis in clinical laboratories}

For more than 25 years there have been sporadic reports, ${ }^{1-3}$ mainly from the USA, of clinical hepatitis apparently acquired by laboratory workers from specimens. Nevertheless, the disease did not appear to be a serious occupational hazard in Britain until laboratory workers became affected by extensive outbreaks of viral hepatitis in haemodialysis units. ${ }^{4}$ Two questions then required answers: how great was the risk? how could it be reduced?

Some diseases are almost completely notified-the risk of tuberculosis, for example, among laboratory workers may be estimated by direct comparison between incidence rates in the group and in the whole population. ${ }^{5}$ In contrast, similar comparisons for hepatitis are unreliable: notifications of infective jaundice are incomplete; cases of anicteric hepatitis are excluded; and no differentiation is made between hepatitis $A$ and B. The results of a postal survey of experience in about 250 British laboratories between 1970 and 1974 have provided valuable data. ${ }^{6} 7$ No attempt was made to compare the incidence of hepatitis with that of the general population, but the study showed that attack rates were highest among technicians, and lowest among porters and domestic and secretarial staff; the overall incidence of clinical hepatitis was 143 per 100000 person years in 1973-4. The annual number of cases remained steady throughout. None of the 73 cases reported in the five years was fatal, and only a quarter required admission to hospital.

More than half of these cases were of hepatitis B-in contrast with a survey in London, which showed that only $20 \%$ of cases among adults in the normal population are hepatitis B. ${ }^{8}$ This suggests that much occupationally acquired hepatitis among laboratory workers is type $\mathrm{B}$. Serological studies ${ }^{910}$ among hospital staff in the USA have shown that workers in close contact with blood have the highest rates of infection with hepatitis B and have confirmed that of all laboratory workers technicians are at the highest risk. Symptomless infections are commoner than clinical hepatitis.

On the available evidence, then, hepatitis is an occupational hazard for laboratory workers; but in Britain the annual 
number of clinical cases is small, and the illnesses appear relatively mild. Even so, the risk can be reduced. The first aim should be to eliminate the hazard arising from outbreaks, and in Britain control and prevention of the disease have been achieved in haemodialysis units, where the numbers of patient carriers of hepatitis B antigen ( $\mathrm{HBsAg}$ ) have been kept to a minimum ${ }^{11}$ and a code of practice has been established. ${ }^{12}$ The background risk to laboratory workers still exists, however, both from patients with hepatitis and (probably more important) from $\mathrm{HBs} A \mathrm{~g}$ carriers with no evidence of hepatitisat least $0 \cdot 1 \%$ of the British population. ${ }^{13}$ Reduction of infection from these sources depends on laboratory workers themselves: detailed advice on appropriate precautions is available, ${ }^{14-16}$ and the laboratory director should issue clear and comprehensive instructions that are not too difficult for staff to put into routine practice. Two points are worth emphasising. All specimens-not only those labelled "high risk" - should be considered potentially infective; and staff must report all accidents to allow the potential danger to be assessed and the indications for prophylaxis to be considered. Human normal immunoglobulin protects against hepatitis A. ${ }^{17}$ Trials in the USA of immunoglobulin with high titre antibody to $\mathrm{HBsAg}$ have shown good, though incomplete, protection. ${ }^{18}{ }^{19}$ Supplies of both materials are held by the Public Health Laboratory Service.

${ }^{1}$ Kuh, C, and Ward, W W E, fournal of the American Medical Association, 1950, 143, 631.

2 Turnbull, M L, and Greiner, D J, Fournal of the American Medical Association, 1951, 145, 965.

${ }^{3}$ Byrne, E B, Fournal of the American Medical Association, 1966, 195, 362.

4 Marmion, B P, and Tonkin, R W, British Medical Bulletin, 1972, 28, no 2, 169.

${ }^{5}$ Harrington, J M, and Shannon, H S, British Medical Fournal, 1976, 1, 759.

6 Grist, N R, Fournal of Clinical Pathology, 1975, 28, 255.

7 Grist, N R, fournal of Clinical Pathology, 1976, 29, 480.

${ }^{8}$ Farrow, L J, et al, British Medical fournal, 1974, 3, 83.

${ }^{9}$ Pattison, C P, et al, American fournal of Epidemiology, 1975, 101, 59.

10 Wruble, L D, et al, Gastroenterology, 1974, 66, 800.

11 Public Health Laboratory Service Survey, British Medical fournal, 1976, $1,1579$.

12 Department of Health and Social Security, Scottish Home and Health Department, Welsh Office, Report of the Advisory Group on Hepatitis and the Treatment of Chronic Renal Failure, 1970-72. London, HMSO, 1972.

13 Payne, R W, Barr, A, and Wallace, J, fournal of Clinical Pathology, 1974, 27, 125.

14 Revised Report of the Advisory Group on Testing for the Presence of Australia (Hepatitis Associated) Antigen and its Antibody. London, DHSS, 1972.

15 Central Pathology Committee, Safety in Pathology Laboratories. London, DHSS, Welsh Office, 1972.

16 Public Health Laboratory Service Monograph Series No 6. London, HMSO, 1974.

17 Pollock, T M, Reid, D, and Smith, G V, Lancet, 1969, 1, 281.

18 Seeff, L B, et al, Lancet, 1975, 2, 939.

19 Grady, G F, and Lee, V A, New England Fournal of Medicine, 1975, 293, 1067.

\section{The end of excellence?}

Throughout the world there are a few hospital complexes where the quality of the care given to patients, the teaching, and the academic research reach the highest possible standards. They take many years, even some generations, to build up, and in Britain for historical reasons a disproportionate number are in the London region. Such centres are relatively few, because excellence requires not only a concentration of medical talent and technological hardware but also enough staff to provide the time needed for the germination and ex- change of ideas, criticism, and consultation. They are expensive, yet the contribution they make to the improvement of standards and advancement of medicine extends far beyond their boundaries. It is for that reason that the new DHSS programme $^{1}$ for sharing resources more fairly among the population of England could prove a tragedy, for it could very easily lead to the decline and fall of the best of English medicine.

The working party that drew up the programme started with the objective of sharing out the resources available to the NHS in such a way "that there would eventually be equal opportunity of access to health care for people at equal risk." In general they have set out to redress the inequalities caused by the excess of doctors and hospitals in the south and east of England and the excess of ill health in the north and west. This imbalance is most marked in London, which has a declining population but still has many of the biggest and newest hospitals housing 12 of the 20 English medical schools. The proposals for redistribution of both revenue and capital are based on population numbers and morbidity; but clearly, too, account has to be taken of the expense to each region of maintaining its teaching hospitals. A complex formula is proposed in the report for a "service increment for teaching" to cover the additional costs to the NHS of providing facilities for clinical teaching. The working party's calculations showed that in teaching hospitals the annual additional cost per student ranged from $£ 3300$ to $£ 19100$. Even after allowance had been made for their high local costs the London schools were all found to be more expensive than the provincial ones with the exception of Oxford, which ranked third in the league table. So the programme also includes a redistribution scheme to bring the costs of the 20 schools closer to average. No specific proposals have been made for the postgraduate institutes and their associated hospitals, but the report suggests that they should be treated in a similar way. The overall effect will be that the four Thames regions which contain the London teaching hospitals will receive a lower proportion of the national spending on the NHS-at a time when every region is struggling to balance its budget.

"There is no escaping the fact," says the working party, "that one centre's excellence may be bought at the price of another's deprivations." This reflects a complete misunderstanding of the influence that centres of excellence have throughout the country. Even so, when resources are limited it seems equitable that they should be shared on the basis of need rather than historical accident: and it is true that since the NHS began the Thames regions have had the thickest slices of the national cake. What is wrong with the working party's plan is that it deals only with resources. The reason the Thames regions have proved so expensive is that London contains not only the teaching and research centres that attract visitors from all over the world but also many more hospitals, doctors, and other staff than can be justified by the needs of its own population. The fantasy solution would be physically to move some of these hospitals-with their staff, equipment, and costs-to the underprivileged regions in the north and west, so reducing the costs of the metropolitan regions to closer to the national average.

That is not, however, what the working party has proposed. Hospital closure is not even mentioned in the report, which stresses that its proposals should be brought into effect slowly: "adjustments should be carefully phased to avoid putting important services at risk." Certainly the transfer of resources that the report has recommended could lead to closure of hospitals in some regions and building of new ones elsewhere (as an extreme example, the "excess costs" of all 12 London 